Obere Extremität 2020 · 15:207-212 https://doi.org/10.1007/s11678-020-00594-w Received: 17 June 2020

Accepted: 4 August 2020

Published online: 11 August 2020

(c) The Author(s) 2020

Patric Raiss - Rainer Neumann

OCM, Munich, Germany

\title{
Bipolar lateralization in reverse shoulder arthroplasty for avoidance of scapular notching
}

\section{Short-term results}

Reverse shoulder arthroplasty (RSA) has become a well-established treatment option for multiple disorders of the shoulder joint [1-4]. Significant pain relief and improvement of function have been published [2-5]. The implant concept introduced by Paul Grammont with a medialized center of rotation on the glenoid side and a $155^{\circ}$ neck-shaft angle on the humeral side has shown good long-term results $[1,6,7]$. Initially, complications such as dislocations and infections were frequent, but decreased substantially with surgeons' growing experience [1]. The radiographic phenomenon of scapular notching describes impingement of the polyethylene liner against the scapular neck, leading to wear debris and potential loosening of components in the long term [8]. Therefore, in recent years implant designs and configurations have been modified. In order to avoid scapular notching, inferior baseplate positioning as well as lateralization on the glenoid side with bone grafting from the humeral head or with metallic augmentation became popular $[9,10]$. Alongside lateralization, bone defects on the glenoid as well as glenoid version and inclination can be addressed by augmentation $[9,10]$. On the humeral side the neck-shaft angle was modified by some manufactures to 145- or 135-degree inclination. First results for lateralization on the glenoid or humeral side are promising; however, results for bipolar lateralization in RSA are limited $[2,11]$.

An excellent option for virtual testing aimed at an "impingement-free" range of motion is represented by CT-based three-dimensional (3D) planning tools [12]. The purpose of this study was to analyze the short-term results of a consecutive cohort of patients treated with RSA and bipolar lateralization who underwent preoperative CT-based 3D planning. The hypothesis was that clinical results improve over time and that scapular notching can be effectively avoided.

\section{Methods}

\section{General information}

Between March 2017 and January 2019, a consecutive series of 38 RSAs with bipolar lateralization were performed in one institution by the first author (PR). In all cases the same RSA system was used (Wright Medical Inc., Memphis, TN, USA). Patients were included in a prospectively recorded database; however, data analysis was performed in a retrospective fashion. All patients were seen in routine clinical controls. Inclusion criteria were the following:

1. preoperative CT-based $3 \mathrm{D}$ planning,

2. treatment with the same reverse shoulder implant,

3. complete clinical and radiographic data, and

4. a minimum follow-up of 12 months.

The 38 replacements were performed in 37 patients. Mean age at the time of surgery was 75 years (range $48-86$ years). There were 28 women and 9 men. The right shoulder was treated 24 times and the left 14 times. Indications for surgery were cuff-deficient shoulders in 22 cases, primary osteoarthritis with severe glenoid erosion in 11, rheumatoid arthritis in 3, and posttraumatic arthritis and instability arthritis in one case each. Mean follow-up was 19 months (range 12-34 months).

\section{Radiographic protocol}

Preoperatively, immediately postoperatively, and at the most recent follow-up, radiographs in two plains (anteroposterior and outlet view) were performed in a standardized fashion. Additionally, CT scans for 3D planning were acquired before surgery according to the protocol. Three-dimensional planning was performed with Blueprint software (Wright Medical Inc.). The goal of preoperative planning was to test different implant configurations as well as implant positions in order to maximize the range of motion and minimize scapular notching. Glenoid morphology was classified according to Bercik et al. [31]. In all cases, the best solution to reach the goal was bipolar lateralization with either bone grafting on the glenoid side (Bony Increased-Offset Reversed Shoulder Arthroplasty, BIORSA; Wright Medical Inc.) or metallic augmentation in combination with an uncemented humeral implant that offers a neck-shaft angle of $145^{\circ}$. Whenever possible, the senior author and surgeon of this study (PR) favored lateralization with bone augmentation (- Figs. 1 and 2 ).

All radiographs were analyzed for implant loosening, incorporation of the 


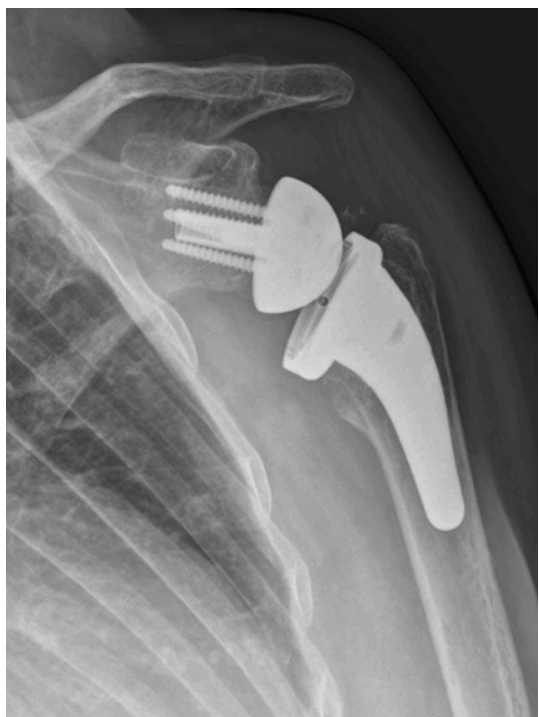

Fig. $1 \Delta$ Anteroposterior radiograph of a reverse shoulder arthroplasty in a 70-year-old woman 24 months after surgery

bone graft, and scapular notching according to the method of Sirveaux et al. [8].

\section{Clinical evaluation}

All patients were examined in a standardized and comparable fashion before surgery and at each follow-up examination. Range of motion was measured in degrees with a standard goniometer for forward flexion and external rotation with the arm hanging at the side and an elbow flexion of $90^{\circ}$. Internal rotation was measured according to the region of patient's back that was reached with the thumb. The Constant and Murley score (CS) was used as a measurement tool $[13,14]$. Additionally, the Subjective Shoulder Value (SSV) was used.

\section{Surgical technique}

All patients were treated under general anesthesia and were placed in the beach chair position. A deltopectoral approach was used and the cephalic vein was prepared laterally. A 1-cm incision of the upper pectoralis major tendon was made in order to visualize the subscapularis tendon correctly, and was repaired after the procedure with nonabsorbable sutures. Tenotomy of the subscapularis tendon was performed and periglenoidal

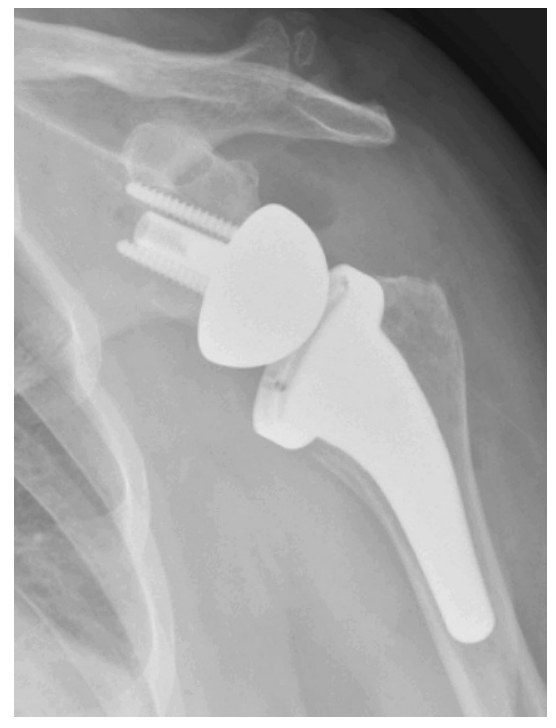

Fig. $2 \Delta$ Anteroposterior radiograph of a reverse shoulder arthroplasty in a 79-year-old woman 18 months after surgery

release was undertaken after placement of a humeral head retractor. Tenodesis of the long head of the biceps was performed systematically. Thereafter, the humeral head was dislocated. A bone graft for lateralization on the glenoid side was prepared with the manufacturer's instruments and resection of the humeral head was performed anatomically in a free-hand technique. Multiple broaches were used for preparation of the proximal humerus according to preoperative planning. After achieving adequate rotational stability of the final broach, the glenoid was exposed. According to the $3 \mathrm{D}$ planning, the central guide pin was placed and slight reaming was performed at the inferior part of the glenoid. Remaining cartilage was removed with a curette. Drill holes were placed with a $2.0-\mathrm{mm}$ drill for better ingrowth of the bone augmentation. The baseplate with a $25-\mathrm{mm}$ post was augmented with the bone graft that was shaped by using a rongeur. According to planning, the angled shaped bone graft was measured with a ruler to have the same lateralization as compared to the planning. The baseplate was impacted and fixed with two compression and two self-locking screws. The diameter of the baseplate was $25 \mathrm{~mm}$ in 28 cases and $29 \mathrm{~mm}$ in 10 cases. In all but one case bone augmentation was performed. In one case a baseplate with
$3 \mathrm{~mm}$ of concentric lateralization (Perform Reverse, Wright Medical Inc.) was used. A 36-mm glenosphere was used in 30 cases and a $42-\mathrm{mm}$ glenosphere in 8 . The humeral head was then exposed, and the humeral tray was positioned. A highoffset $(3.5-\mathrm{mm})$ tray was used in 20 cases and a low-offset $(1.5-\mathrm{mm})$ tray was used in 18 cases. Tray position 6 was chosen in 30 cases and position 12 in 8 . Care was taken that the tray did not overlap the highest point of the greater tuberosity, to avoid overlengthening of the arm. A + 6$\mathrm{mm}$ liner was used in all cases after trial reduction. The final implant was placed thereafter. An uncemented short stem was used in all cases, with a neck-shaft angle of $145^{\circ}$. The subscapularis tendon was repaired with 6-8 nonabsorbable sutures. The wound was closed in layers and patients were immobilized in a sling for 2 days. After 2 days patients were allowed to remove the sling and to use the arm according to their pain level. Free range of motion was allowed 2 days after surgery.

\section{Statistics}

The paired t-test was used to compare preoperative with most recent follow-up outcome (flexion, external and internal rotation, and CS). The level of significance was set at $p<0.05$.

\section{Results}

\section{Clinical results}

All patients were evaluated postoperatively by a fellowship-trained orthopedic surgeon who was not involved in the surgeries. There was a significant increase in all measured clinical parameters. For example, mean forward flexion increased from a mean of $75^{\circ}$ (range $20-150^{\circ}$ ) preoperatively to $151^{\circ}$ (range $120-180^{\circ}$ ) postoperatively $(p<0.001)$, and the mean CS from 21 (range 4-42) to 71 points (range 51-93 points) postoperatively $(p<0.001)$. Mean SSV increased from $21 \%$ (range $10-40 \%$ ) preoperatively to $83 \%$ (range $20-100 \%$ ) postoperatively.

All clinical results are shown in - Table 1. 
Obere Extremität 2020 • 15:207-212 https://doi.org/10.1007/s11678-020-00594-w

(c) The Author(s) 2020

P. Raiss · R. Neumann

\section{Bipolar lateralization in reverse shoulder arthroplasty for avoidance of scapular notching. Short-term results}

Abstract

Introduction. Reverse shoulder arthroplasty (RSA) has become a well-established treatment option for multiple disorders of the shoulder joint. In recent years, implant designs and configurations have been modified in order to improve function and avoid complications. Lateralization on the glenoid and the humeral side has been described to improve function and decrease radiographic scapular notching. Data on the clinical and radiographic results of bipolar lateralization in RSA are lacking.

Methods. In 38 cases, RSA was performed using an uncemented humeral short-stem component with a $145^{\circ}$ neck-shaft angle in combination with bone lateralization on the glenoid side (Bony Increased-Offset Reversed Shoulder Arthroplasty, BIO-RSA; Wright Medical Inc., Memphis, TN, USA). Mean follow-up was 19 months (range 12-34 months). Patients were followed clinically using the Constant score as well as range of motion for shoulder flexion and external rotation. Radiographs in two different plains were analyzed for implant seating and the occurrence of scapular notching.

Results. There was a significant increase in all measured clinical parameters. Forward flexion increased from a mean of $75^{\circ}$ preoperatively to $151^{\circ}$ postoperatively, and mean Constant score increased from 21 to 71 points postoperatively $(p<0.001)$. Glenoid notching of grade 1 according to Sirveuax was observed in 3 out of 35 cases (9\%); no grade 2, 3 , or 4 notching was present. Revision surgery was necessary in one case (3\%).

Conclusion. RSA with bipolar lateralization leads to excellent clinical outcomes, low complication rates, and low rates of radiographic scapular notching. Longer follow-up and prospective randomized trials are needed. Level of evidence. Level IV.

Keywords

BIO-RSA · Scapular notching · Arthroplasty, replacement, shoulder · Postoperative complications - Shoulder joint · Joint dislocations . Bone transplantation

\section{Bipolare Lateralisierung in der inversen Schulterendoprothetik zur Vermeidung von Skapula- Notching. Kurzzeitergebnisse}

\section{Zusammenfassung}

Einleitung. Die inverse Schulterendoprothetik (RSA) hat sich zu einer etablierten Behandlungsoption für mehrere Erkrankungen des Schultergelenks entwickelt. In den letzten Jahren wurden die Implantatdesigns und -konfigurationen modifiziert, um die Funktion zu verbessern und Komplikationen zu vermeiden. Eine Lateralisierung auf Glenoidund Humerusseite wurde beschrieben, um die Funktion zu verbessern und das radiographische Skapular-Notching zu verringern. Es fehlen Daten zu den klinischen und röntgenologischen Ergebnissen der bipolaren Lateralisation bei RSA.

Methoden. In 38 Fällen wurde die RSA mit einer unzementierten humeralen Kurzschaftkomponente mit einem $145^{\circ}$ Hals-Schaft-Winkel in Kombination mit einer Knochenlateralisation auf Glenoidseite durchgeführt („Bony Increased-Offset Reversed Shoulder Arthroplasty", BIO-RSA; Wright Medical Inc., Memphis, TN, USA). Der durchschnittliche Follow-up betrug 19 Monate (Range: 12-34 Monate). Die Patienten wurden unter Verwendung des ConstantScores sowie des Bewegungsumfangs für Schulterbeugung und Außenrotation klinisch nachbeobachtet. Die Röntgenaufnahmen in zwei verschiedenen Ebenen wurden hinsichtlich des Implantatsitzes und des Auftretens eines Skapula-Notching analysiert. Ergebnisse. Es gab einen signifikanten Anstieg bei allen gemessenen klinischen Parametern. Die Vorwärtsbeugung stieg von einem Mittelwert von $75^{\circ}$ präoperativ auf $151^{\circ}$ postoperativ, und der mittlere ConstantScore erhöhte sich postoperativ von 21 auf 71 Punkte $(p<0,001)$. Ein glenoidales Notching
Grad 1 nach Sirveuax wurde in 3 von 35 Fällen ( $9 \%$ ) beobachtet; es lag kein Notching Grad 2, 3 oder 4 vor. In einem Fall war eine Revisionsoperation erforderlich (3\%). Schlussfolgerung. Die RSA mit bipolarer Lateralisation führt zu hervorragenden klinischen Ergebnissen, niedrigen Komplikationsraten und geringen Raten von radiographischem Skapula-Notching. Längere Nachbeobachtungszeiten und prospektivrandomisierte Studien sind erforderlich. Evidenzgrad. Level IV

\section{Schlüsselwörter} BIO-RSA · Skapula-Notching · Arthroplastik, Endoprothetik, Schulter - Postoperative Komplikationen - Schultergelenk . Gelenkluxationen $\cdot$ Knochentransplantation

\section{Radiographic results}

Glenoid morphology showed an A1 glenoid in 16 cases, an A2 in 8, a B1 in 3, and a B2 in 11. No signs of implant loosening were detected on standard radiographs, neither on the humeral nor on the glenoid side. Full incorporation of the bone augmentation on the glenoid was seen in 33 out of 34 cases. In one case partial osteolysis of the bone graft was detected
25 months after surgery in a rheumatoid patient (- Fig. 3). However, this patient was very satisfied with the clinical result and no signs of radiographic implant loosening were found.

Glenoid notching was observed in 3 out of 35 cases $(9 \%)$, with grade 1 according to Sirveuax; no grade 2, 3, or 4 notching was present. No case of humeral loosening was detected.

\section{Revisions}

In one case revision surgery was necessary (3\%). This patient had a massive cuff-tear arthropathy with a huge inferior bone spur on the glenoid neck (• Fig. 4). Three months after RSA (• Fig. 5) this patient suffered a non-traumatic dislocation in combination with a fatigue fracture of the acromion (• Fig. 6). Closed reduction was performed and the patient was placed 


\section{Originalarbeit}

\section{Table 1 Clinical data of patients}

\begin{tabular}{|c|c|c|c|c|c|}
\hline & $\begin{array}{l}\text { Mean value preopera- } \\
\text { tive }\end{array}$ & Range preoperative & $\begin{array}{l}\text { Mean value postopera- } \\
\text { tive }\end{array}$ & Range postoperative & $p$-value \\
\hline Flexion $\left({ }^{\circ}\right)$ & 75 & $20-150$ & 151 & $120-180$ & $<0.001$ \\
\hline External rotation $\left({ }^{\circ}\right)$ & 13 & $-20-70$ & 54 & $20-80$ & $<0.001$ \\
\hline Internal rotation ${ }^{a}$ & 2 & $0-4$ & 5 & $2-8$ & $<0.001$ \\
\hline Constant score (points) & 21 & $4-42$ & 71 & $51-93$ & $<0.001$ \\
\hline Pain (points) & 2 & $0-5$ & 14 & $10-15$ & $<0.001$ \\
\hline Activity (points) & 7 & $4-12$ & 15 & $12-20$ & $<0.001$ \\
\hline Mobility (points) & 11 & $4-20$ & 28 & $14-36$ & $<0.001$ \\
\hline
\end{tabular}

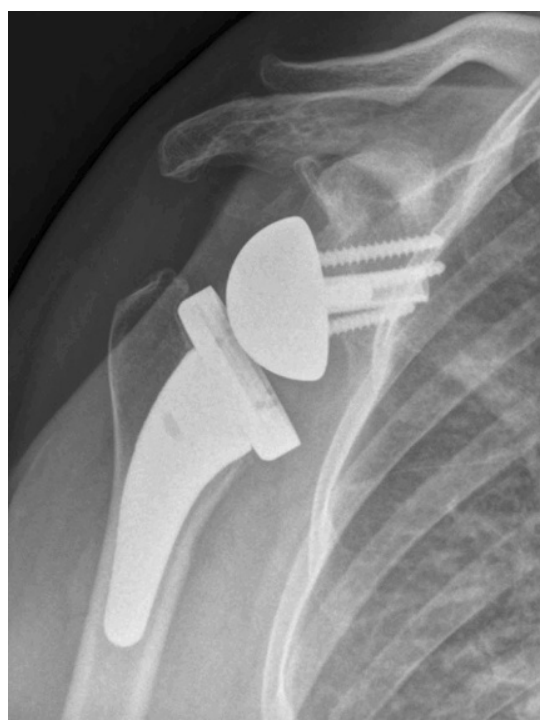

Fig. $3 \Delta$ Anteroposterior radiograph 28 months after reverse shoulder arthroplasty in a 62-yearold woman with partial resorption of the bone graft under the baseplate

in a sling for 4 weeks; however, re-dislocation occurred. Revision was performed 6 months after the initial surgery with a liner $3 \mathrm{~mm}$ higher on the humeral side and a lateralizing glenosphere ( $\bullet$ Fig. 7). No re-dislocation has occurred to date (12 months after revision).

\section{Discussion}

RSA has become a very frequent surgical procedure for multiple degenerative disorders of the shoulder joint. In former days, this implant concept was used exclusively in patients with cuff-tear arthropathy [7]. However, as the initially high complication rates decreased over time, indications were expanded to other diagnoses including massive rotator cuff

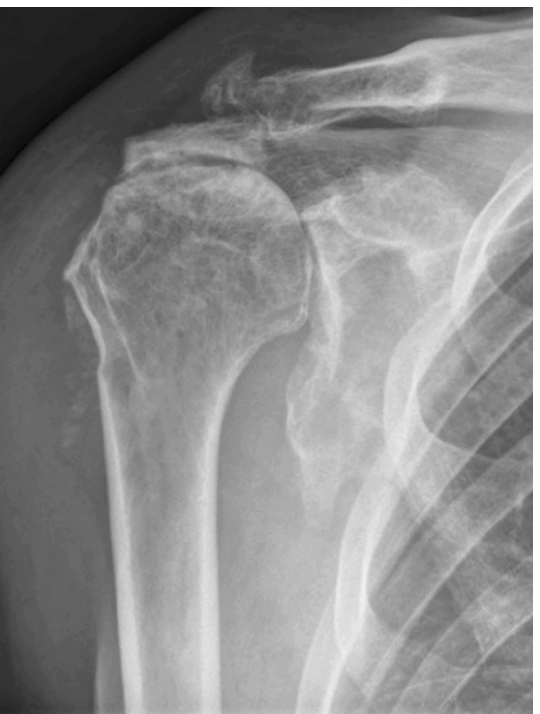

Fig. $4 \Delta$ Anteroposterior radiograph of a cuff-tear arthropathy with a bone spur at the inferior part of the glenoid. This patient was 85 years old

tears [15], rheumatoid arthritis [16, 17], posttraumatic arthritis [5, 18-21], and primary osteoarthritis [22]. Compared to anatomic shoulder replacement, RSA also relieves pain and improves shoulder function, although rotation (especially internal rotation) may be compromised. A frequent complication in anatomic replacement is radiographic loosening of the glenoid component, particularly in the long term [23, 24]. Loosening of the glenoid component in RSA is a rare complication in primary conditions with good bone stock on the scapula [25]. However, the radiographic phenomenon of scapular notching was frequently detected in several studies $[1,8,26]$. The contact between the humeral liner and the neck of the scapula frequently leads to

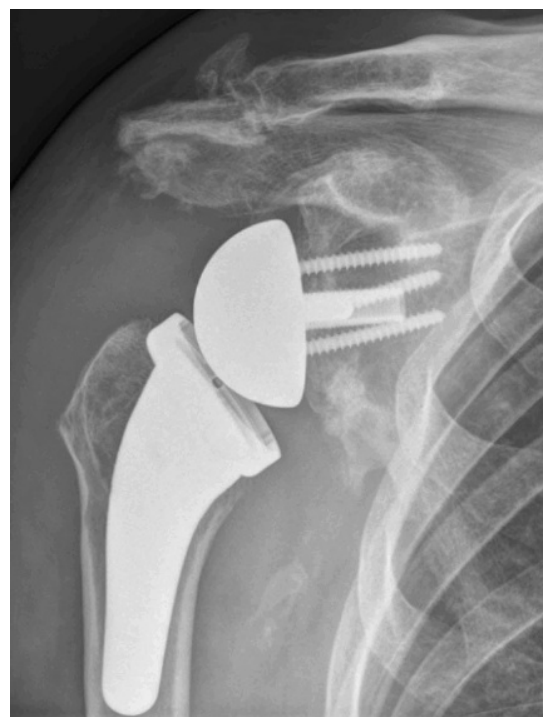

Fig. $5 \Delta$ Anteroposterior radiograph of the patient in $\bullet$ Fig. 4 after reverse shoulder arthroplasty

bone erosion and wear of the polyethylene liner. Polyethylene wear particles may induce osteolysis around both the humeral and glenoid components, leading to possible loosening [27]. Different implant modifications have been developed in recent years in order to avoid scapular notching. The first option to achieve a greater notching-free range of motion is reduction of the neck-shaft angle on the humeral side. Historically, the neck-shaft angle in RSA was $155^{\circ}$. Modern implants usually offer a lower and/or modular neck-shaft angle of $135^{\circ}$ or $145^{\circ}$. Due to the lower angle, notching of the liner becomes less likely and the component is less distalized and more lateralized. The second option to reduce notching is lateralization on the glenoid 


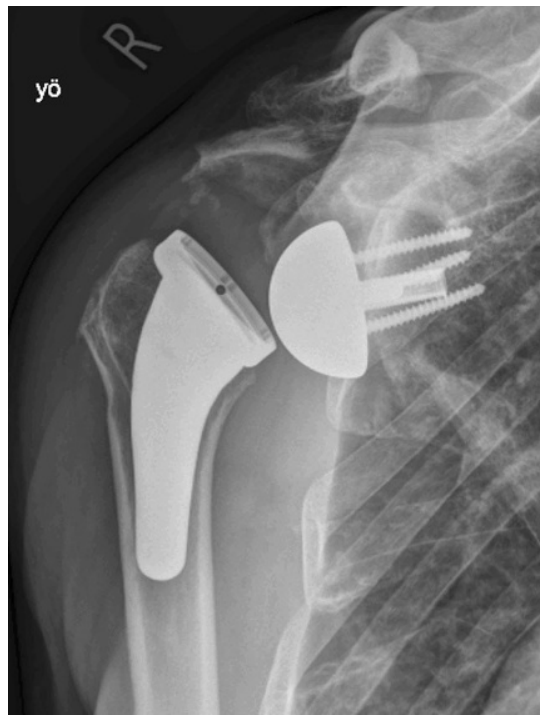

Fig. $6 \Delta$ Anteroposterior radiograph of the patient in 0 Figs. 4 and 5 after dislocation and fatigue fracture of the acromion

side. This can be achieved by an augmented baseplate (with metal or bone), a lateralized glenosphere, or both $[2,10]$.

Several studies have been published to show that lateralized humeral and glenoid components have lower rates of radiographic scapular notching compared to medialized implants $[3,11]$. However, data on bipolar lateralization are limited.

Werthel et al. published a descriptive analysis of different frequently used RSA systems and found 28 different configurations in 22 different implants and a high variability in global lateralization with between 13.1-35.8mm [28].

Recently, Boileau et al. published their 5-10-year results of the BIO-RSA concept in a cohort of 143 consecutive patients [2]. All patients received biologic augmentation on the glenoid side with a bone graft from the humeral head in order to lateralize the component and lengthen the scapular neck. They found graft incorporation in $96 \%$ of cases and grade 3 and 4 notching according to Sirveaux was present in $18 \%$. Low body mass index, superior inclination of the baseplate, and a flush glenosphere without inferior overhang were risk factors for scapular notching. They hypothesized that a humeral component with a neck-shaft angle $<155^{\circ}$ in combination with a lateralized baseplate should lead to less notching.

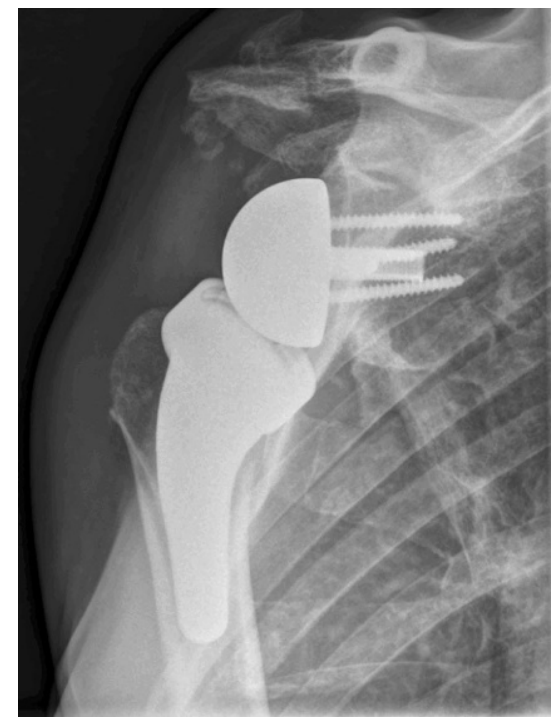

Fig. $7 \Delta$ Anteroposterior radiograph of the patient in - Figs. 4 and 5, and - Fig. 61 year after revision surgery

The results of the current study seem to support this statement, as we found an overall low frequency of scapular notching in only $9 \%$ of cases, all of which were grade 1 . However, it must be mentioned that Boileau et al. [2] published mid- to long-term results, whereas the current investigation presents short-term results only.

One strength of the current study is that all patients underwent preoperative CT-based 3D planning and multiple implant configurations were tested for each patient virtually in order to achieve the best scenario for an impingement-free range of motion. In all cases bipolar lateralization was the most effective solution to avoid notching and achieve the best possible range of motion in all planes. $\mathrm{Pa}$ tients were treated according to preoperative planning and concordance between planning and implantation was high, as previously shown by Raiss et al.

The effectiveness of the philosophy of bipolar lateralization with a short-stem humeral component with a $145^{\circ}$ neck-shaft angle in combination with bone augmentation on the glenoid side is underlined by the study of Lädermann et al. [29]. These authors recently published their results on the effect of humeral and glenosphere design on range of motion based on 3D planning software. They compared 30 different implant configura- tions and found that only 5 out of 30 combinations were able to restore $>50 \%$ of the anatomic range of motion in all directions. Only a lateralized neck-shaft angle $\left(145^{\circ}\right)$ in combination with eccentric, large, or lateralized spheres was able to restore the range of motion accordingly.

Another aspect of lateralization in addition to reduction of scapular notching and improvement of range of motion is implant stability. In a biomechanical study Pastor et al. showed that particularly lateralization on the glenoid side significantly increased anterior stability of the artificial joint in different abduction angles [30]. Only a minor effect on stability was found for a lower humeral neck-shaft angle.

One patient in the current series suffered a dislocation which was related to underestimation of the pathology by the surgeon, as the severe cuff-tear arthropathy led to a huge inferior spur on the scapula neck that was not adequately removed during the first operation and which probably levered out the humeral component.

The limitations of the current study are its monocentric and retrospective design as well as the short follow-up and relatively low number of patients. Longer follow-up and a higher number of patients are necessary to adequately compare the findings to the abovementioned studies. CT scans were not acquired postoperatively to analyze incorporation of the bone grafts. However, the current study comprises a cohort of patients who were treated consistently with preoperative $3 \mathrm{D}$ planning and the same implant by one surgeon.

\section{Conclusion}

Reverse shoulder arthroplasty with bipolar lateralization leads to good and satisfying clinical outcomes, low complication rates, and low rates of radiographic scapular notching. 


\section{Corresponding address}

Prof. Dr. Patric Raiss, M.D.
OCM
$\begin{aligned} & \text { Steinerstraße 6, 81369 Mu- } \\ & \text { nich, Germany } \\ & \text { patric.raiss@ocm- } \\ & \text { muenchen.de }\end{aligned}$

\section{Compliance with ethical guidelines}

Conflict of interest. P. Raiss is a consultant for Wright Medical Inc. R. Neumann declares that he has no competing interests.

All procedures performed in studies involving human participants or on human tissue were conducted via inclusion into the DVSE endoprosthesis register in accordance with the ethical standards of the institutional and/or national research committee and the 1975 Helsinki declaration and its later amendments or comparable ethical standards. Informed consent was obtained from all individual participants included in the study.

Open Access This article is licensed under a Creative Commons Attribution 4.0 International License, which permits use, sharing, adaptation, distribution and reproduction in any medium or format, as long as you give appropriate credit to the original author(s) and the source, provide a link to the Creative Commons licence, and indicate if changes were made. The images or other third party material in this article are included in the article's Creative Commons licence, unless indicated otherwise in a credit line to the material. If material is not included in the article's Creative Commons licence and your intended use is not permitted by statutory regulation or exceeds the permitted use, you will need to obtain permission directly from the copyright holder. To view a copy of this licence, visit http://creativecommons.org/licenses/by/4.0/.

\section{References}

1. Bacle G, Nove-Josserand L, Garaud P, Walch G (2017) Long-term outcomes of reverse total shoulder arthroplasty: a follow-up of a previous study. J Bone Joint Surg Am 99:454-461. https:// doi.org/10.2106/JBJS.16.00223

2. Boileau P et al (2020) Bony increased-offsetreverse shoulder arthroplasty: 5 to 10 years' followup. J Shoulder Elbow Surg. https://doi.org/10. 1016/j.jse.2020.02.008

3. Sanchez-Sotelo J, Athwal GS (2020) How to optimize reverse shoulder arthroplasty for irreparable cuff tears. Curr Rev Musculoskelet Med. https:// doi.org/10.1007/s12178-020-09655-7

4. Waterman BR et al (2020) Comparative clinical outcomes of reverse total shoulder Arthroplasty for primary cuff tear athropathy versus severe glenohumeral osteoarthritis with intact rotator cuff: a matched-cohort analysis. J Am Acad Orthop Surg. https://doi.org/10.5435/JAAOS-D19-00493

5. Raiss P et al (2018) Reverse shoulder arthroplasty for type 1 sequelae of a fracture of the proximal humerus. Bone Joint J 100-B:318-323. https://doi. org/10.1302/0301-620X.100B3.BJJ-2017-0947. R1

6. Levigne Cet al (2011) Scapular notching in reverse shoulder arthroplasty: is it important to avoid it and how? Clin Orthop Relat Res 469:2512-2520. https://doi.org/10.1007/s11999-010-1695-8

7. Favard L et al (2011) Reverse prostheses in arthropathies with cuff tear: are survivorship and function maintained over time? Clin Orthop Relat Res 469:2469-2475. https://doi.org/10.1007/ s11999-011-1833-y

8. Sirveaux F et al (2004) Grammont inverted total shoulder arthroplasty in the treatment of glenohumeral osteoarthritis with massive rupture of the cuff. Results of a multicentre study of 80 shoulders. JBone Joint SurgBr 86:388-395

9. Boileau P, Moineau G, Roussanne $Y$, O'Shea K (2011) Bony increased-offset reversed shoulder arthroplasty: minimizing scapular impingement while maximizing glenoid fixation. Clin Orthop Relat Res 469:2558-2567

10. ViraniNAetal (2013) Reverse shoulderarthroplasty components and surgical techniques that restore glenohumeral motion. J Shoulder Elbow Surg 22:179-187. https://doi.org/10.1016/j.jse.2012. 02.004

11. Raiss $P$ et al (2019) Postoperative radiographic findings of an uncemented convertible short stem for anatomic and reverse shoulder arthroplasty. J Shoulder Elbow Surg 28:715-723. https://doi. org/10.1016/j.jse.2018.08.037

12. Boileau P et al (2018) Automated three-dimensional measurement of glenoid version and inclination in arthritic shoulders. J Bone Joint Surg Am 100:57-65. https://doi.org/10.2106/JBJS.16. 01122

13. Constant CR (1997) An evaluation of the ConstantMurley shoulder assessment. J Bone Joint Surg Br 79:695-696

14. Constant CR, Murley AH (1987) A clinical method of functional assessment of the shoulder. Clin Orthop Relat Res 1987(214):160-164

15. Ek ET, Neukom L, Catanzaro S, Gerber C (2013) Reverse total shoulder arthroplasty for massive irreparable rotator cuff tears in patients younger than 65 years old: results after five to fifteen years. J Shoulder Elbow Surg 22:1199-1208. https://doi. org/10.1016/j.jse.2012.11.016

16. Mangold DR, Wagner ER, Cofield RH, SanchezSotelo J, Sperling JW (2019) Reverse shoulder arthroplasty for rheumatoid arthritis since the introduction of disease-modifying drugs. Int Orthop 43:2593-2600. https://doi.org/10.1007/ s00264-019-04373-3

17. Cho CH, Kim DH, Song KS (2017) Reverse shoulder arthroplasty in patients with rheumatoid arthritis: a systematic review. Clin Orthop Surg 9:325-331. https://doi.org/10.4055/cios.2017.9.3.325

18. Willis M et al (2012) Proximal humeral malunion treated with reverse shoulder arthroplasty. J Shoulder Elbow Surg 21:507-513. https://doi. org/10.1016/j.jse.2011.01.042

19. Raiss Petal (2017) Reverse arthroplasty for patients with chronic locked dislocation of the shoulder (type 2 fracture sequela). J Shoulder Elbow Surg 26:279-287. https://doi.org/10.1016/j.jse.2016. 05.028

20. Raiss P et al (2016) Reverse shoulder arthroplasty for malunions of the proximal part of the humerus (type-4 fracture sequelae). J Bone Joint Surg Am 98:893-899. https://doi.org/10.2106/JBJS.15. 00506
21. Raiss P et al (2014) Reverse shoulder arthroplasty for the treatment of nonunions of the surgical neck of the proximal part of the humerus (type-3 fracture sequelae). J Bone Joint Surg Am 96:2070-2076. https://doi.org/10.2106/JBJS.N. 00405

22. Mizuno N, Denard PJ, Raiss P, Walch G (2013) Reverse total shoulder arthroplasty for primary glenohumeral osteoarthritis in patients with a biconcave glenoid. J Bone Joint Surg Am 95:1297-1304. https://doi.org/10.2106/JBJS.L. 00820

23. Fox TJ et al (2009) Survival of the glenoid component in shoulder arthroplasty. J Shoulder Elbow Surg 18:859-863

24. Papadonikolakis A, Neradilek MB, Matsen FA 3rd (2013) Failure of the glenoid component in anatomic total shoulder arthroplasty: a systematic review of the English-language literature between 2006 and 2012. J Bone Joint Surg Am 95:2205-2212. https://doi.org/10.2106/JBJS.L. 00552

25. Rojas J, Choi K, Joseph J, Srikumaran U, McFarland EG (2019) Aseptic glenoid baseplate loosening after reverse total shoulder arthroplasty: a systematic review and meta-analysis. JBJS Rev 7:e7.https://doi.org/10.2106/JBJS.RVW.18.00132

26. Melis B etal (2011) An evaluation of the radiological changes around the Grammont reverse geometry shoulder arthroplasty after eight to 12 years. JBone Joint Surg Br 93:1240-1246

27. Raiss P et al (2014) Radiographic changes around humeral components in shoulder arthroplasty. J Bone Joint Surg Am 96:e54. https://doi.org/10. 2106/JBJS.M.00378

28. Werthel JD et al (2019) Lateralization in reverse shoulder arthroplasty: a descriptive analysis of different implants in current practice. Int Orthop 43:2349-2360. https://doi.org/10.1007/s00264019-04365-3

29. Ladermann A et al (2020) Effect of humeral stem and glenosphere designs on range of motion and muscle length in reverse shoulder arthroplasty. Int Orthop 44:519-530. https://doi.org/10.1007/ s00264-019-04463-2

30. Pastor MF et al (2020) Anatomic factors influencing the anterior stability of reverse total shoulder arthroplasty. J Shoulder Elbow Surg. https://doi. org/10.1016/j.jse.2020.03.045

31. Bercik MJ et al (2016) A modification to the Walch classification of the glenoid in primary glenohumeral osteoarthritis using three-dimensional imaging. JShoulderElbowSurg 25(10):1601-1606. https://doi.org/10.1016/j.jse.2016.03.010 